\title{
Artrite reumatoide com sete anos de evolução sem seguimento médico
}

Hélder José Ferreira Gomes*

\section{RESUMO}

Introdução: A artrite reumatoide é uma poliartrite inflamatória, simétrica e periférica de etiologia desconhecida, envolvendo preferencialmente as articulações das mãos e dos pés. Caso não seja atempadamente diagnosticada e tratada, a deformação e destruição articular tornam-se permanentes, com deterioração funcional importante. Por conseguinte, a ausência de tratamento atempado poderá resultar na incapacidade de realização de tarefas da vida diária, absentismo laboral ou mesmo desemprego. Descrição do caso: Utente de sexo feminino, com 36 anos, recorreu a uma primeira consulta na USF, referindo, como queixas principais, uma grande deformação articular, afetando predominantemente as articulações do punho e dedos das mãos, dos pés e dos joelhos. Para além disso, referia uma grande limitação funcional nas atividades de vida diária (AVD), causadas pela grande deformação articular associada a astenia e anedonia. Todo este quadro, arrastado ao longo de anos, não foi avaliado e não teve acompanhamento médico por, segundo a doente, não ter sido permitido pelo ex-companheiro.

Comentários: O diagnóstico tardio de atrite reumatoide conduz a destruição articular permanente e irreversível. $O$ padrão de comportamento submisso inerente ao transtorno da personalidade dependente é fator de risco para comportamentos abusivos nas relações interpessoais.

Palavras-chave: Artrite reumatoide; Poliartrite; Manifestações extra-articulares; Violência doméstica; Transtorno da personalidade dependente.

\section{INTRODUÇÃO}

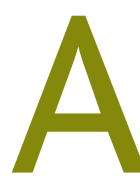
artrite reumatoide é uma doença inflamatória sistémica caracterizada por poliartrite inflamatória, simétrica e periférica de etiologia desconhecida, envolvendo preferencialmente as articulações das mãos e dos pés. ${ }^{1-2}$ Conduz a uma deformidade particular, por alongamento de tendões e ligamentos com destruição articular, erosão cartilagínea e óssea. É de destacar que outras articulações podem estar envolvidas, nomeadamente os joelhos.

Realce-se que, não sendo atempadamente diagnosticada e tratada, a deformação e destruição articular tornam-se permanentes, implicando, assim, uma deterioração funcional importante. Pode levar à incapacidade de realização de tarefas da vida diária, com consequente absentismo laboral e possibilidade de conduzir ao desemprego.

*Médico Interno de Medicina Geral e Familiar. USF Conde de Oeiras.
A artrite reumatoide faz diagnóstico diferencial com outras doenças reumatológicas, nomeadamente: artrite psoriática, doenças inflamatórias intestinais com atingimento articular e lúpus eritematoso sistémico.

O exame físico completo é essencial para avaliação das articulações envolvidas e caracterização da eventual limitação da mobilidade articular. Inicialmente, a inflamação é predominantemente peri-articular e simétrica, atingindo, como referido anteriormente, as mãos ao nível de articulações metacarpofalângicas e interfalângicas e os pés ao nível das metatarso-falângicas. Mais tarde, a lesão articular torna-se permanente com deformidade articular irreversível. ${ }^{2}$ Além disso, podem inclusive surgir manifestações extra-articulares, nomeadamente cardíacas, pulmonares e vasculares, entre outras.

Para o diagnóstico é importante, inicialmente, solicitar o fator reumatoide (FR) e o anticorpo antipeptídeo citrulinado cíclico (anti-CCP). ${ }^{1}$ Este último não é possível ser requisitado ao nível dos cuidados de saúde primários. A positividade a um dos testes 
isoladamente aumenta a sensibilidade diagnóstica. Se ambos os anticorpos forem positivos, a especificidade do diagnóstico será necessariamente superior. No entanto, é de destacar que até $50 \%$ dos doentes com artrite reumatoide poderão ter os anticorpos inicialmente negativos. Os anticorpos antinucleares, se negativos, são úteis para excluir lupus eritematoso sistémico. Assim, numa fase inicial é importante solicitar hemograma completo, função renal e hepática, velocidade de sedimentação e PCR (ambos tipicamente elevados na apresentação). $\mathrm{O}$ raio-X das articulações das mãos, punhos e pés deve ser obtido para monitorização basal da progressão da doença. ${ }^{2}$ A ecografia ou ressonância magnética, embora não estejam estabelecidas por rotina, identificam sinovite com maior precisão, sendo a sensibilidade na deteção de erosões ósseas superior ao raio-X. ${ }^{2}$

$\mathrm{O}$ American College of Rheumatology (ACR) e a European League Against Rheumatism (EULAR) emitiram, em 2010, critérios de classificação com vista a identificar doentes num estadio precoce da doença. Estes critérios consideram as articulações envolvidas, preferencialmente as pequenas articulações, serologia, reagentes de fase aguda, duração dos sintomas e a serologia. Para doentes com sinovite inflamatória indiferenciada, quanto maior o número de pontos maior a probabilidade de se estar perante a doença. ${ }^{3}$

Os transtornos da personalidade são padrões de comportamento inadaptativos e que implicam um sofrimento pessoal intenso. $\mathrm{O}$ transtorno da personalidade dependente caracteriza-se por uma dependência psicológica dos outros, com um comportamento predominantemente submisso. Segundo o DSM-5, este transtorno de personalidade é caracterizado por uma "uma necessidade generalizada e excessiva de cuidados, que leva a um comportamento submisso, e ao medo de separação". ${ }^{4}$

Este transtorno da personalidade tem início na idade adulta e é fator de risco para comportamentos abusivos nas relações interpessoais. ${ }^{5-6}$ De acordo com o DSM-5, ${ }^{4}$ este transtorno da personalidade tem uma prevalência na população adulta de $0,49 \%$, sendo que já se referiram prevalências em torno de 1 a $2 \%{ }^{7}$

\section{DESCRIÇÃO DO CASO}

Identificação e história pessoal

Mulher de 36 anos, do sexo feminino, separada, ope- radora de call center, mas desempregada aquando da consulta. Natural de Oeiras, posteriormente passou a residir em Sintra até início de 2018, altura em que regressou a Oeiras, onde reside em casa dos pais.

Como antecedentes pessoais teve um aborto espontâneo aos cinco meses de gestação, aos 28 anos.

\section{Caracterização familiar}

A utente integra uma família nuclear, em fase VI do ciclo familiar de Duvall de classe socioeconómica III (média), segundo a escala de Graffar.

A doente é filha única e, após a separação, reside com os pais.

\section{História da doença atual}

\section{Consulta programada 23/02/2018}

A 23/02/2018 recorreu a uma primeira consulta na USF. Apresentava uma grande deformação articular das articulações do punho, dos dedos das mãos, dos pés e dos joelhos. Além disso, referia uma grande limitação funcional nas atividades de vida diária (AVD), inerente à grande deformação articular associada a astenia e anedonia.

O quadro clínico teve início aos 28 anos após um aborto espontâneo aos cinco meses de gestação. Referia um agravamento progressivo das queixas álgicas e da rigidez articular, que era de predomínio matinal nos últimos últimos anos. Concomitantemente, a gonalgia bilateral foi aumentando de intensidade. Mencionava o surgimento de fotossensibilidade, de fenómeno de Raynaud nas articulações das mãos e dos pés e cianose dos pés no último ano e, mais recentemente, o surgimento de ulcerações cutâneas nos pés.

Justificava não ter procurado acompanhamento médico para este quadro arrastado ao longo de anos por não lhe ter sido permitido pelo ex-companheiro. É de salientar que a doente se inscreveu na USF e recorreu a consulta por insistência dos pais.

No exame objetivo inicial era possível observar uma grande deformação articular grave e irredutível, com desvio ulnar dos dedos em flexão rígida. Apresentava limitação funcional dos ombros, não conseguindo fazer abdução dos membros superiores. Ao nível dos joelhos constatou-se valgismo e rigidez articular e também deformação articular grave e irredutível dos pés e tornozelos associada a ulceração plantar. Apresentava fácies 


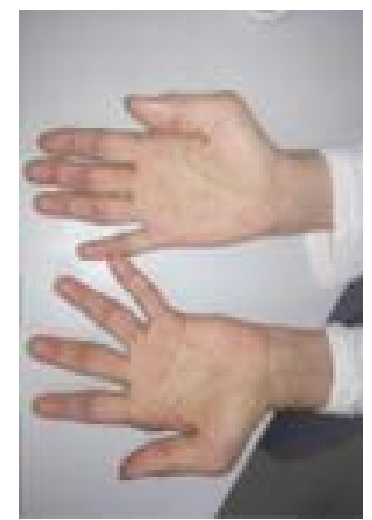

Figura 1. Deformação articular grave e irredutível.

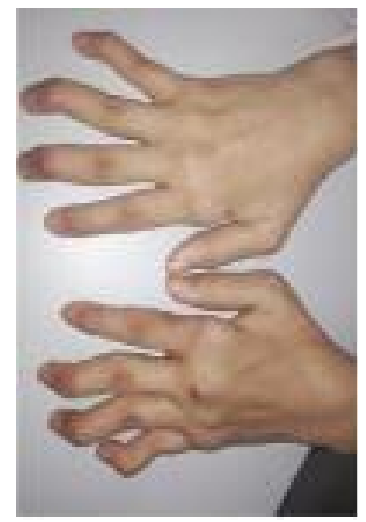

Figura 2. Desvio ulnar dedos em flexão rígida.

pouco expressivo com notório edema periorbitário, mucosas ligeiramente descoradas, mas hidratadas, e pele seca.

Com os dados disponíveis relativos às articulações envolvidas e a duração dos sintomas colocou-se a hipótese de se tratar de um caso de artrite reumatoide e, desta forma, iniciou-se o tratamento com prednisolona $5 \mathrm{mg}$, duas vezes por dia, associado a naproxeno $500 \mathrm{mg}$, tendo sido solicitado o estudo complementar de diagnóstico inicial de artrite reumatoide. Embora não integre a abordagem da artrite reumatoide, decidiu-se solicitar avaliação da função tiroideia para estudo complementar da astenia referida.

Dos resultados obtidos destacou-se uma anemia normocítica normocrómica com hemoglobina de 11,6g/dL, VGM 95,0fL e HCM 31,7pg. A função renal era normal. Da função tiroideia verificou-se uma elevação da TSH: 83,55mUI/L compatível com hipotiroidismo. Relativa- mente aos marcadores inflamatórios, a VS 99mm/h estava aumentada e PCR normal e destacava-se a presença de um fator reumatoide (FR) positivo - $354 \mathrm{UI} / \mathrm{mL}$, anticorpos antinucleares (ANA) - positivo forte, anticorpo anti-tireoglobulina (Ac-TG) positivo e o anticorpo anti-peroxidase (anti-TPO) positivo $-270 \mathrm{u} / \mathrm{ml}$.

\section{Evolução}

Face ao exposto foi possível estabelecer dois problemas de relevo: artrite reumatoide e hipotiroidismo de etiologia autoimune.

Assim sendo, optou-se pela continuação de tratamento com prednisolona $5 \mathrm{mg}$ duas vezes por dia, associada a levotiroxina na dose $1,6 \mathrm{mg} / \mathrm{kg} / \mathrm{dia}$, perfazendo 88 microgramas por dia. Foi referenciada para consulta de reumatologia com caráter urgente, a qual foi marcada em duas semanas e na qual foi proposto $o$ internamento, que a doente recusou.

A doente tem mantido seguimento na USF e em consulta de reumatologia, com melhoria significativa da funcionalidade, das queixas álgicas e normalização da função tiroideia.

\section{COMENTÁRIO}

A artrite reumatoide, na ausência de diagnóstico e tratamento atempado, pode conduzir a deformação e destruição articular permanente. A deterioração funcional, inerente a um diagnóstico tardio, pode levar à incapacidade de realização de tarefas da vida diária, ao absentismo laboral e à possibilidade de conduzir ao desemprego. Assim, perante a suspeita de um caso de artrite reumatoide é importante o encaminhamento para uma consulta de reumatologia numa fase precoce.

Os corticoides são importantes para redução da inflamação, podendo, no entanto, mascarar os sintomas e dificultar o diagnóstico. Por esse motivo, devem ser evitados antes de o doente ser observado em reumatologia. Neste caso, dada a deformação poliarticular evidente, a utilização de corticoides não iria mascarar a apresentação clínica. No entanto, o valor de PCR no início do quadro clínico era, provavelmente, falsamente normal, porque a doente já se encontrava a fazer corticoterapia quando fez a análise.

Os anti-inflamatórios não esteroides podem ser indicados no controlo de sintomas. No entanto, não têm efeito na evolução da doença. ${ }^{2}$ 
A cirurgia com aplicação de prótese articular pode melhorar a dor e a função articular. Nunca é demais destacar a promoção de exercício físico e fisioterapia como papel chave no controlo da doença.

O exercício físico deve ser fundamentalmente dinâmico, com amplitude de movimentos, no mínimo duas vezes por semana, com períodos de pelo menos $20 \mathrm{mi}-$ nutos.

A fisioterapia é benéfica para a dor e rigidez a curto prazo, associada à terapia ocupacional. Durante as consultas deverá ser feita educação para a saúde sobre a proteção articular.

O padrão de comportamento submisso por parte da utente configura um provável transtorno da personalidade dependente. Este padrão de comportamento é fator de risco para comportamentos abusivos nas relações interpessoais. ${ }^{6}$ De facto, em grande medida, o facto de o ex-companheiro assumir a decisão em áreas importantes da sua vida configura um traço de personalidade dependente. Desta forma, este caso, em que nos é referido que o ex-companheiro não permitia nenhuma observação médica, poderá eventualmente ser enquadrado num caso de violência doméstica, sendo a personalidade da utente fator de risco para a perpetuação destes comportamentos.

Importa também referir a definição de caso de violência doméstica, que refere: "maus tratos físicos ou psíquicos, incluindo castigos corporais, privações da liberdade e ofensas sexuais:

a) Ao cônjuge ou ex-cônjuge;

b) A pessoa de outro ou do mesmo sexo com quem o agente mantenha ou tenha mantido uma relação de namoro ou uma relação análoga à dos cônjuges, ainda que sem coabitação;

c) A progenitor de descendente comum em $1 .^{\circ}$ grau;

d) A pessoa particularmente indefesa, nomeadamente em razão da idade, deficiência, doença, gravidez ou dependência económica, que com ele coabite".

Estamos em pleno século XXI e existem ainda casos que se arrastam no tempo, sem qualquer tipo de acompanhamento, com consequências graves e permanentes. A compreensão do contexto familiar, neste caso, torna-se fundamental, assim como a intervenção pre- coce e atempada para minimizar o impacto da doença. Várias estratégias de psicoterapia adaptativas podem ser utilizadas para lidar com os traços de personalidade dependentes, como uma abordagem baseada em psicoterapia psicodinâmica e estratégias cognitivo-comportamentais, com enfoque no autoconceito e funcionamento interpessoal. A psicoterapia é fundamental para a aquisição de competências de assertividade e gestão da ansiedade. O principal objetivo é o alívio do medo de abandono, tão característico desta perturbação de personalidade, com acompanhamento regular. ${ }^{9}$

\section{REFERÊNCIAS BIBLIOGRÁFICAS}

1. Wasserman A. Rheumatoid arthritis: common questions about diagnosis and management. Am Fam Physician. 2018;97(7):455-62.

2. Venables PJ. Diagnosis and differential diagnosis of rheumatoid arthritis. UpToDate [Internet]; 2019 Nov 25 [updated 2020 Sep]. Available from: https://www.uptodate.com/contents/diagnosis-and-differentialdiagnosis-of-rheumatoid-arthritis

3. Scott DL, Wolfe F. Rheumatoid arthritis. Lancet. 2010;376(9746):P1094108.

4. American Psychiatric Association. Diagnostic and statistical manual of mental disorders. 5th ed. Washington: APA; 2013.

5. Simonelli A, Parolin M. Dependent personality disorder. In: Zeigler-Hill $V$, Shackelford T, editors. Encyclopedia of personality and individual differences [Internet]. Cham: Springer; 2017. Available from: https://link.springer.com/referenceworkentry/10.1007\%2F978-3-31928099-8_578-1

6. Loas G, Cormier J, Perez-Diaz F. Dependent personality disorder and physical abuse. Psychiatry Res. 2011;185(1-2):167-70.

7. Trull TJ, Jahng S, Tomko RL, Wood PK, Sher KJ. Revised NESARC personality disorder diagnoses: gender, prevalence, and comorbidity with substance dependence disorders. J Pers Disord. 2010;24(4):412-26.

8. Decreto-Lei n. ${ }^{\circ}$ 48/95, de 15 de março. Diário da República. 1995;Série I-A(63).

9. Ferri FF. Ferri's clinical advisor 2020. Elsevier; 2019. ISBN 9780323672542

\section{Conflito de interesses}

O autor declara não ter quaisquer conflitos de interesse.

\section{ENDEREÇO PARA CORRESPONDÊNCIA}

Hélder José Ferreira Gomes

E-mail: gomes_helder@outlook.com

https://orcid.org/0000-0002-7744-2777

Recebido em 24-09-2019

Aceite para publicação em 17-06-2020 


\section{ABSTRACT}

\section{RHEUMATOID ARTHRITIS WITH SEVEN YEARS OF EVOLUTION WITHOUT MEDICAL FOLLOW-UP}

Introduction: Rheumatoid arthritis is an inflammatory, symmetrical and peripheral disease of unknown etiology, preferably involving the joints of the hands and feet. If it is not diagnosed and treated at a suitable time, deformation and joint destruction become permanent, with important functional deterioration. Therefore, the absence of timely treatment may result in the inability to perform daily living tasks, absenteeism, or even unemployment.

Case report: A 36-year-old female patient referred for a first visit to the USF, referring, as main complaints, a great joint deformation, predominantly affecting the wrist and fingers, toes, and knees. In addition, she referred to a major functional limitation in activities of daily living (ADL), caused by the great joint deformation associated with asthenia and anhedonia. This whole situation, dragged along for years, was not evaluated and had no medical follow-up because, according to the patient, it was not allowed by the former partner.

Comments: Late diagnosis of rheumatoid arthritis leads to joint destruction, permanent and irreversible. The submissive behavior pattern, inherent in dependent personality disorder, is a risk factor for abusive behaviors in relationships.

Keywords: Rheumatoid arthritis; Polyarthritis; Extra-articular manifestations; Domestic violence; Dependent personality disorder. 